\title{
LETTER TO Measuring the lung age of smokers
}

\section{THE EDITOR}

\author{
*James Hansen ${ }^{a}$ \\ a Department of Medicine, Harbor-UCLA \\ Medical Center, California, USA \\ *Correspondence: \\ Dr James Hansen, \\ Department of Medicine \\ Harbor-UCLA Medical Center \\ Torrance, California 90509, \\ USA \\ Tel: +310-222-3803 \\ E-mail: jhansen@labiomed.org
}

28th June 2010

(c) 2010 Primary Care Respiratory Society UK. All rights reserved

\section{Dear Sir,}

Congratulations to Dr Newbury and her colleagues ${ }^{1}$ for their investigation, development, and use of a new equation for lung age to compare with that of Morris and Temple. ${ }^{2}$ Informing smokers of their spirometric lung age should be a valuable incentive allowing practitioners to help their afflicted smokers stop their addictive behaviour. ${ }^{3}$

In pursuit of the goal of improving lung age prediction equations and reducing the damaging effect of cigarette smoking and other toxic inhalants, a simplified formula for lung age was very recently published by our group. ${ }^{4}$ The formula uses each individual's actual forced expiratory volume in one second $\left(\mathrm{FEV}_{1}\right)$ and forced vital capacity (FVC). Subtracting the actual $\% \mathrm{FEV}_{1} / \mathrm{FVC}$ from the $\%$ predicted $\mathrm{FEV}_{1} / \mathrm{FVC}$ and multiplying that difference by three yields the added lung age. For example, in a 40 year-old patient with a predicted $\% \mathrm{FEV}_{1} / \mathrm{FVC}$ of $82 \%$ and an actual $\% \mathrm{FEV}_{1} / \mathrm{FVC}$ of $76 \%$, the lung age would be 6 times $3=$ 18 years older than the patient's actualage.

The predicted $\% \mathrm{FEV}_{1} / \mathrm{FVC}$ can be calculated as follows: ${ }^{5}$

$$
\% \mathrm{FEV}_{1} / \mathrm{FVC}=98.8-0.25 \times \text { years }-1.79 \times \mathrm{FVC} \text { in } \mathrm{L}
$$

Since the difference between the actual $\% \mathrm{FEV}_{1} / \mathrm{FVC}$ of never-smoking men and women of several ethnicities can be explained primarily by the differences in age and FVC of each individual. Importantly, in normal populations, the ratio of $\% \mathrm{FEV}_{1} / \mathrm{FVC}$ has much less variability than absolute measures of other spirometric volumes or flows.

Figure 1. Comparison of lung age formulas. The differences in mean lung ages from actual ages in 2178 never-smokers and 1377 current-smokers are shown in groups of men and women over twenty-year spans. The Morris and Temple ${ }^{2}$ equations and Newbury et al. ${ }^{1}$ equations based on FEV 1 are different for each gender; the Hansen et al. ${ }^{4}$ equation [change in lung age years = (predicted - actual) \% FEV $1 / F V C \times 3$ ] is not gender-specific. All equations, on average, have higher lung ages for groups of current-smokers than neversmokers; these differences increase with advancing age. On average, the Morris and Temple equations calculate never-smokers' ages as less than their actual ages; Newbury et al. equations calculate never-smokers' ages higher than their actual age; Hansen et al. equations calculate never-smokers' ages close to their actual ages.

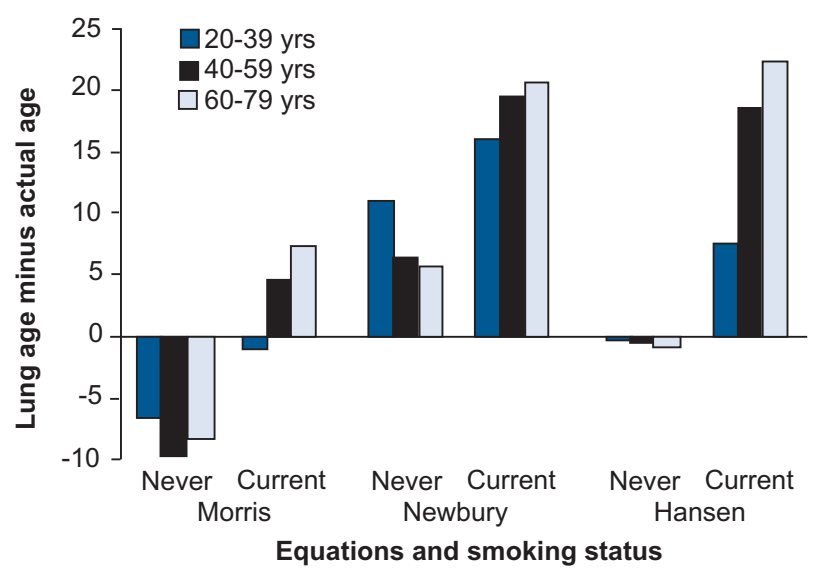


Using Morris and Temple's FEV 1 equation, the new equations of Newbury et al., and the simple lung age equation given above, ${ }^{4}$ lung ages of 2178 white never-smokers and 1377 white current-smokers from the third USA National Health and Nutrition Evaluation Survey were compared. The findings are displayed in Figure 1. For every decade, the current-smokers' lung ages are higher than those of the never-smokers for each equation. However, the mean lung ages of each decade derived from the simple equation best reflects the actual ages of never-smokers. Thus, the simple lung age equation is likely to be broadly useful. It would be valuable to see how well this equation fits with other never- and current-smokers previously and currently being evaluated.

\section{Conflict of interest declaration}

None.

\section{References}

1. Newbury W, Newbury J, Briggs N, Crockett A. Exploring the need to update lung age equations. Prim Care Resp J 2010;19(3):242-7 http://dx.doi.org/ 10.4104/pcrj.2010.00029

2. Morris J, Temple W. Spirometric "lung age" estimation for motivating smoking cessation. Prev Med 1985;14(5):655-62.

3. Parkes $G$, Greenhalgh T, Griffen M. Dent R. Effect on smoking quit rate of telling patients their lung age: the Step2quit randomised controlled trial. $B M J$ 2008;336(7644):598-600. http://dx.doi.org/10.1136/bmj.49503.582396.25

4. Hansen JE, Sun XG, Wasserman K. Calculating gambling odds and lung ages for smokers. Eur Respir J 2010;35:776-80. http://dx.doi.org/10:1183/ 09031936.00107709.

5. Hansen, JE, Sun XG, Wasserman K. Ethnic and sex-free formulae for detection of airway obstruction. Am J Respir Crit Care Med 2006;174:493-8. http://dx.doi.org/10.1164/rccm/200604-5170C on June 15, 2006

\section{Authors' reply}

We thank Dr Hansen for his interest ${ }^{1}$ in our paper. ${ }^{2}$

In his comparison of the lung age equations published by Morris et al., ${ }^{3}$ Newbury et al. ${ }^{2}$ and Hansen et al., ${ }^{4}$ Dr Hansen appears to have applied each equation to the Caucasian neversmokers and current smokers from the third USA National Health and Nutrition Evaluation Survey (NHANES III) dataset. For the never-smokers, this comparison examines how closely the equation can predict the actual age of the subject. The Morris equations under-predict actual age across each 20-year age bracket, which is a similar result to our own analysis. In the same group, the Newbury equations appear to over-predict actual age, while the Hansen equation very closely predicts the actual age of each age bracket. Dr Hansen claims this indicates that his equation best reflects the mean ages of the never-smoking group. We would rather suggest that this result is due to the Hansen equation being applied to the same sample that was used to generate the equation. This is a circular argument; the Hansen equations predict the actual mean age of the subjects from whom they were derived. Conversely, we did not apply our lung age equations to the dataset which generated them ${ }^{5}$ for this very reason, but used an independent dataset.

Dr Hansen correctly states that all the equations predict lung ages that are higher in the current smokers than in the never- smokers, although there are obvious differences between equations. In the current smoker group, the Morris et al. equations predict the lowest lung ages. We feel that this reinforces our own results, although we found that Morris et al. predicted the current smokers' mean lung age to be lower than actual age. The Newbury and the Hansen equations both predict greater lung ages in this current smoker group. This further reinforces the conclusion in our paper that the Morris lung age equations under-predict lung age, for which we discussed several possible reasons. It would be interesting to see results of further comparisons of these lung age equations using an independent dataset.

The Morris lung age equations have been incorporated into the software of many spirometry instruments, and users should be aware of the applicability of these equations in 2010, given that they were created using data that is now 40 years old. The NHANES III data that Dr Hansen's equations are based on were collected between 1988 and 1994, and are also now approximately 20 years old. In their editorial in this issue dated 27th June 2010, ${ }^{6}$ Quanjer and Enright also point out the "need to use equations that fit the local population". Clearly, further research in lung age use is warranted.

\section{References}

1. Hansen J. Letter to the Editor. Measuring the lung age of smokers. Prim Care Resp /2010;19(3):286-7. http://dx.doi.org/10.4104/pcrj.2010.00048

2. Newbury W, Newbury J, Crockett A. Exploring the need to update lung age equations. Prim Care Resp J 2010;19(3):242-7. http://dx.doi.org/10.4104/ pcrj.2010.00029

3. Morris J, Temple W. Spirometric "lung age" estimation for motivating smoking cessation. Prev Med 1985;14(5):655-62.

4. Hansen J, Sun X-G, Wasserman K. Calculating gambling odds and lung ages for smokers. Eur Respir J 2010;35:776-80. http://dx.doi.org/ 10.1183/09031936.00107709

5. Newbury W, Crockett A, Newbury J. A pilot study to evaluate Australian predictive equations for the Impulse Oscillometry System. Respirology 2008;13(7):1070-75. http://dx.doi.org/10.1111/j.1440-1843.2008.01375.x

6. Quanjer P, Enright P. Should we use 'lung age'? Prim Care Resp J 2010; 19(3):197-9. http://dx.doi.org/10.4104/pcrj.2010.00045

*Wendy Newbury ${ }^{a}$, Jonathan Newbury ${ }^{b}$, Alan Crockett ${ }^{c}$

a Discipline of General Practice, School of Population Health and Clinical Practice, University of Adelaide; Spencer Gulf Rural Health School, University of Adelaide and University of South Australia

b Professor, Spencer Gulf Rural Health School, University of Adelaide and University of South Australia

c Associate Professor, Primary Care Respiratory Research Unit, Discipline of General Practice, School of Population Health and Clinical Practice, University of Adelaide

*Correspondence:

Spencer Gulf Rural Health School, PO Box 3200, Port Lincoln

South Australia, Australia

Tel: +61 419324529 Fax: +61 886832095

E-mail: wendy.newbury@adelaide.edu.au

doi:10.4104/pcrj.2010.00048 